\title{
A Study of the Impact of Value-Added Efficiency on Profitability and Market Value in the Indian Pharma Industry
}

\author{
Shireen Rosario \\ Lecturer, College of Commerce $\mathcal{E}$ Business Administration, \\ Dhofar University, PB 2509, Salalah 211, Oman \\ Chandra Sen Mazumdar \\ Assistant Professor, Department of Management Studies, \\ MS Ramaiah University of Applied Sciences, New BEL Road, \\ Bangalore, India
}

DOI: https://doi.org/10.36941/ajis-2022-0019

\begin{abstract}
The aim of this paper is to highlight the growing influence of Intellectual Capital (IC) on the profitability and market valuation, especially in knowledge-based industries. The scope of this paper is restricted to the Indian Pharmaceutical Industry, which is highly dependent on IC. This study employs the measure of Value-Added Intellectual Coefficient (VAIC) to assess impact of IC on the profitability and market valuation and to assess the growth of VAIC and its components among the companies over the years selected for the study. The study uses 22 Pharmaceutical companies listed in the Bombay Stock Exchange for a period of 12 years from the financial year 2008-09 to 2019-20. By using Path Analysis, the study demonstrates that the components of VAIC have an impact on the ROCE and market value, which has only grown as compared to earlier studies $\mathcal{E}$ years. The study also demonstrates that high sales and profits need not necessarily result in high VAIC.
\end{abstract}

Key words: Human capital, Indian, Intellectual Capital, Market Value, Value Added

\section{Introduction}

Some decades ago, corporate earnings used to reflect a company's health, its future course, and the likely outcome in the coming years. Earning indicated the value created by enterprise. However, since the early 1980s, the investment in traditional assets like plant \& machinery, structures, factories, inventory etc. in many developed/developing countries have been steadily falling and the investment rate in intangible assets have been increasing ( $\mathrm{Gu} \& \mathrm{Lev}, 2017)$. This transformation in the business model, known as information revolution, came to be an irreversible trend affecting every aspect of economy. This great change spearheaded by information systems and the internet, saw radical changes in the business, deregulations, mergers and acquisition, privatization, and increased globalization, which brought along enhanced competition in every aspect of economy. The only way to survive in such a competitive environment was by process innovation, primarily by investing in intangible assets ( $R \& D$, brands, business processes). 


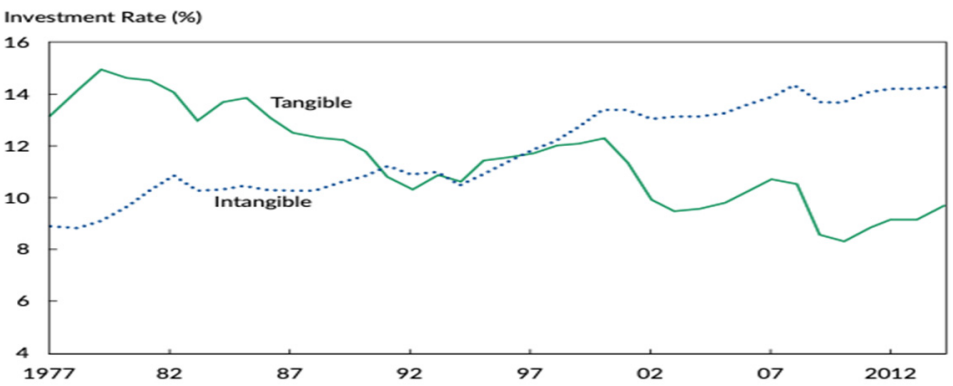

Figure 1: Systematically falling rate of investment in tangible assets and increased investment in intangible assets in the US. Source: Contribution by Prof. Carol Corrodo \& Charles Hulten as reflected in Gu \& Lev (2017)

As against the quantum of goods produced that determined the value creation until a few decades ago, in the $21^{\text {st }}$ century it is not only the quantity of goods produced that is important, but also the knowledge content that is built in. Intellectual capital is synonymous with employees who carry this knowledge, a skill set that can be transformed into products and services that create value. Today, companies carry two resources i.e., intellectual capital and physical capital to create value.

According to Pulic (2005), if the management of a firm decides to be more productive and profitable with its existing resources, the firm must introduce measures that will indicate how productive each element / segment has been and this will push employees transform their skills into value creation. Firms that are very successful, participate in the competitive environment by utilizing intellectual capital. The question is not what the company has, but what it can. IC is seen as a strategic tool. Intellectual capital is a great development in the $21^{\text {st }}$ century.

The degree of dependency on IC varies among industries. However, in some industries like Information Technology, Pharmaceuticals, Banking, Hospitality, Education etc. the dependency on IC is more pronounced.

India is one of the leading producers of pharmaceuticals in the world. With the cost of production that is low (approximately 33\% lower than that of the US), the continued R\&D investments by Pharma companies and the boost that is given by the government of India, the competitive advantage of India has increased over the years. This has led to increased exports of pharmaceutical products to the rest of the world (exports reached US\$16.28 billion in FY 2020). Indian pharma exports reach more than 200 countries in the world, the US being the top export destination. India has a fantastic pool of technically qualified biotech and pharmaceutical workforce and is second in the world in terms of workforce and its quality. Indian pharma sector is expected to grow at a CAGR of $\mathbf{2 2 . 4 \%}$ (Source: IBEF (India Brand Equity Foundation) report, 2020). Since the implementation of TRIPS agreement in 2005 , the industry has been extensively engaged in R\&D and increasing production capacities.

As the Indian Pharmaceutical Industry is highly dependent on Intellectual Capital, the objective of this paper is to (1) Examine the impact of VAIC and its components on Return on Capital Employed (ROCE) \& market valuation (2) Analyze, evaluate and rank of VAIC and its components in the Indian Pharmaceutical Industry

\section{Literature Review}

During the last two decades researchers have been extensively investigating the influence of IC on the profitability and market value of firms. Some researchers perceive that the gap linking market capitalization and book value of capital is largely contributed by the IC. 
The focus on IC in the corporate world was brought by TA Stewart who published an article in the Fortune Magazine titled "Brain Power - how intellectual capital is becoming America's most valued asset" According to Stewart, companies that do not pay attention to knowledge, are not paying attention to business.

Kamath (2008) chose 25 top firms of the pharma sector in India for the period 1996- 2006. Three dependent variables were used in this study i.e., ROA, ATO and M/B. While ROA was the proxy for profitability measure of the company, where ROA is the measure of the return obtained on the total asset employed, ATO (Asset Turnover Ratio) looked at the productivity of the firm and M/B (market to book ratio) was a proxy for the market valuation of the firm. The results indicated that the Human Capital had a profound influence on the profitability and productivity of the firms.

The study like the one conducted by Kamath (2008) was also done by Tandon \& Purohit (2015) who examined the correlation between market valuation, productivity, and profitability (being the traditional methods of measuring financial well-being) and IC. Based on earlier research which indicated that if the sections of VAIC (HCE, SCE, CEE) are considered separately, one would obtain better results / have greater explanatory power, than taking only VAIC as an aggregate, in this study also the researchers consider the components separately. The study employs ROA as an independent variable that reflects the profitability of the given firm. As the study considers the three components of VAIC separately, it develops three separate sets of hypotheses. The study investigates 10 companies listed in IT and Pharmaceutical industries and listed in BSE (Bombay Stock Exchange) for the period 2008-09 to 2011-12. The overall result, arrived at from correlation and multiple linear regression is that the relationship between the three components and profitability, productivity and market valuation is limited and do not support the proposed hypothesis. The study supports the research conducted by Shaban \& Kavida (2013), where it was found that Capital Employed Efficiency (CEE) has a high level of positive correlation with $\mathrm{M} / \mathrm{B}$ ratio. In India, firms follow the traditional accounting measures and hence, results based on intangible assets like IC are not very robust.

Ghosh \& Mondal (2009) studied 8o companies in the IT and pharma sectors in India to verify the impact of IC on profitability. The researchers developed the efficiency measures using VAIC. The study could only explain the bearing of IC on profitability but not on market valuation and productivity in the selected industries in India.

The impact of IC on traditional measures were also examined in the Iranian Pharma industry by Mehralian et al (2012), who drew samples for the period 2004 to 2009. The result of this study was mixed. The researchers who employed correlation and regression methods along with ANN (artificial neutral network) discovered that IC has a positive influence on profitability but not on productivity and market valuation in Iranian companies. It was also confirmed that physical capital played a major role in this influence and not, the other variables.

Maji \& Chakrabarty (2019) studied the impact of intellectual capital on the financial performance of listed Indian commercial banks for the period 2000 to 2016 by employing quantile regression model in panel data set up. The authors opined that the panel data mean regression model is inadequate to explore the true impact of intellectual capital. Results of the study suggested that the positive impact of intellectual capital is significant only at upper tails of the distribution of bank performance and that the impact of intellectual capital becomes stronger with higher degree of precision when the banks' value goes up.

Apart from studies conducted on specific knowledge-based sectors, researchers have investigated the influence of IC on different sectoral firms listed in respective stock exchange.

Nagaraj \& Vinay (2016) did a study on Indian Companies for the years 2007 to 2009 to empirically test the impact of intangible assets, financial policies, and financial performance on firm value. By using path analysis, the researchers established that financial policies, financial performance, and intangible assets have an influence on firm value.

Kamath (2015) based her study on 30 firms from S\&P BSE sensitive index to evaluate the influence of IC on the market valuation and financial results. The firms chosen were across manufacturing and service sectors. The period of sample was 2008-09 to 2012-13. The author used the 
VAIC methodology and multiple linear regression to establish that profitability of the firms under study is clearly influenced by the productivity of its IC. The research also revealed that among the sections of VAIC, the HCE and SCE have a bigger bearing on profitability than CEE.

Some researchers have questioned the very basis of VAIC arguing that it only shows the efficiency of Human capital, Structural capital and Physical Capital employed and that IC is very wide to be expressed in VAIC (Stahle et al, 2011). Researchers have also gone ahead in modifying the VAIC model, arguing that it leaves out the impact of R\&D and Advertising / marketing. Xu \& Liu (2020) investigated the influence of VAIC and its components on the performance of South Korean manufacturing sector. The authors go one step further to investigate the influence of extended VAIC and compare the results with those obtained from the original VAIC. In the extended VAIC method, the researchers include R\&D expenditure and Marketing \& Advertising Expenditure as additional variables. The conclusion of the authors is that the extended VAIC is the better indicator of efficiencies as compared to the original VAIC and that IC is an important component in the value creation in the manufacturing firms in the Korean context.

Overall, the studies show that the results of the impact of VAIC on various parameters is varied. While studies indicate a positive impact of VAIC and its elements on the profitability and productivity, its impact on market valuation is limited. This is because in certain countries like India, investors still depend on the traditional measures of profitability indicators and still look at the outcome from physical assets. Further, the accounting disclosures are not developed to include the IC in the financial statements, from where the investors can make their decisions. Excepting Maji \& Chakrabarty (2019) who employed quantile regression and Nagaraj \& Vinay (2016) who used path analysis, other studies have employed linear regression models and have presumed the association to be consistent across firms.

\section{Methodology}

To carry out the analysis accurately and in a systematic manner, we first explain the construction of variables.

\subsection{Independent Variables (VAIC E its components)}

One of the popular methods of measuring IC is the "Value Added Intellectual Coefficient" (henceforth VAIC) method that was designed and developed by Ante Pulic (Pulic,1998 and 2oooa and 20oob). VAIC adopts the method of measuring IC directly, based on published financial statements. Pulic (200oa and b) measured firm's market value as a combination of efficiency of both tangible assets and IC employed - both resources without which any firm cannot survive.

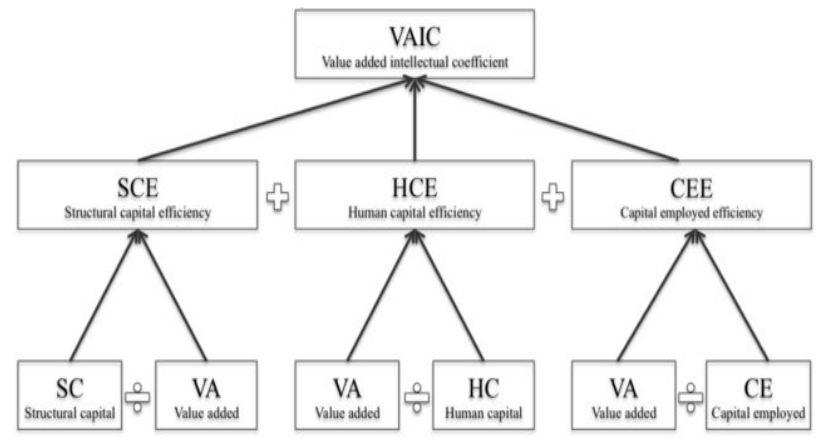

Figure 2: Construction of Value-Added Intellectual Coefficient. Source: Pulic, 2004 
VAIC is based on two key resources i.e., Physical assets employed and the Intellectual Capital (IC). The intellectual capital consists of Human Capital and Structural Capital.

Human Capital = All employees, their abilities to add value and their organization .

Structural Capital = Information systems, Labs, Market intelligence etc.

The starting point of VAIC is the calculation of VA or Value Added. Creation of Value Added can be expressed as follows:

$\mathrm{VA}=$ Output - Input (in input, human expenditure is not considered, as this element is considered as capital).

Public (2004) proposed a formula of calculating Value Added, which is the most popular method today, which is explained as follows:

$\mathrm{VA}=\mathrm{OP}+\mathrm{EC}+\mathrm{D}+\mathrm{A}$

Where, VA is Value Added ; OP $=$ Operating Profit $; \mathrm{EC}=$ Employee Cost ; $\mathrm{D}=$ Depreciation; $\mathrm{A}=$ Amortization

The components of VAIC are three - HCE (Human capital efficiency)- this measures the efficiency of the human capital, SCE (structural capital efficiency)- this measures the efficiency of the structural capital and CEE (Capital employed efficiency)- which measures the efficiency of the physical assets employed by the company. These three aspects together constitute VAIC. Algebraically it can be summed as follows:

$\mathrm{VAIC}=\mathrm{HCE}+\mathrm{SCE}+\mathrm{CEE}$

Each element of VAIC is calculated as follows:

$\mathrm{HCE}=\mathrm{VA} / \mathrm{HC} ; \mathrm{SCE}=(\mathrm{VA}-\mathrm{HC}) / \mathrm{VA} ; \mathrm{CEE}=\mathrm{VA} / \mathrm{CE}$

Here, $\mathrm{VA}=$ Value Added, $\mathrm{HC}=$ Human Capital, $\mathrm{CE}=$ Capital Employed

It is to be noted that though the importance of physical capital has been decreasing with the rise of knowledge capital, its importance cannot be ruled out. Intellectual capital must go in tandem with physical capital and only then we get the value added of products and services.

\subsection{Mediating variables}

We used Return on Assets (ROA), Market Capitalization and Leverage as mediating variables.

Return on Assets (ROA): Profit after tax / total assets employed.

Market Capitalization: Natural log of (Market price as on 31st March X Number of outstanding shares)

Leverage: (Long term + short Term debt) / Total Assets employed as per the balance sheet.

\subsection{Dependent variables}

The study uses two dependent variables. Return on Capital Employed (ROCE) is a proxy for profitability and Market to Book Ratio (MB Ratio) is the proxy for Market Value.

ROCE: Profit after taxes / (Equity Capital + Reserves + Borrowings).

MB Ratio: (Market price of the share as of $31^{\text {st }}$ March X Number of outstanding shares) / (Equity Capital + Reserves)

\subsection{Collection of data}

The workings of this paper are based on the data of 12 years (Financial year ended 31.3.2009 to financial year ended 31.3.2020) of the selected pharmaceutical companies in India. As VAIC can be calculated only if there is profit, only profit-making companies have been selected. The data is obtained from www.screener.in, which compiles the financial results of Indian companies. In terms of sales, these companies represent $78 \%$ of the total sales of pharma companies listed on the Bombay Stock Exchange as on 31.3.2021. As the annual results for the financial year 2020-21 for all companies under study were not published at the time of writing this paper, the data has been restricted up to 
the financial year 2019-20.

Table 1: Selected pharmaceutical companies

\begin{tabular}{|c|l|c|l|}
\hline Sl. & \multicolumn{1}{|c|}{ Name of the Company } & Sl. & \multicolumn{1}{|c|}{ Name of the Company } \\
\hline 1 & Aarthi Drugs Ltd. & 12 & Granules India Ltd. \\
\hline 2 & Abbott Laboratories & 13 & IPCA Laboratories Ltd. \\
\hline 3 & Ajantha Pharma Ltd. & 14 & JB Chemicals \& Pharmaceuticals Ltd. \\
\hline 4 & Aurobindo Pharma Ltd. & 15 & Jubilant Life Sciences Ltd. \\
\hline 5 & BIOCON Ltd. & 16 & Lupin Ltd. \\
\hline 6 & Cadila Healthcare Ltd. & 17 & NATCO Pharma Ltd. \\
\hline 7 & CIPLA Ltd & 18 & Pfizer \\
\hline 8 & Divi's Laboratories Ltd. & 19 & Sanofi India Ltd \\
\hline 9 & Dr. Reddy's Laboratories Ltd. & 20 & Strides Pharma Sciences Ltd. \\
\hline 10 & Glaxo SmithKline Pharmaceuticals Ltd. & 21 & Sun Pharmaceuticals Industries Ltd. \\
\hline 11 & Glenmark Pharmaceuticals Ltd. & 22 & Torrent Pharmaceuticals Ltd. \\
\hline
\end{tabular}

Analysis in this paper proceeds as follows:

1. Firstly, Value Added and VAIC \& its components (HCE, SCE, CEE) are calculated

2. By way of Path Analysis, the influence of VAIC and its elements on Profitability is tested. Based on the work of Tandon \& Purohit (2015) who used the components of VAIC independently and obtained better results than using VAIC as one measure, we use HCE, SCE and CEE as independent variables. Leverage, Market Cap and ROA are used as mediating variables. ROCE is used as a dependent variable.

3. With the help of Path Analysis, the influence of VAIC and its elements on Market value is tested. Step No. 2 is repeated here, excepting that MB Ratio is used as a proxy for market value.

4. The company wise and year wise results of HCE, SCE, CEE and VAIC are sorted by the year 2020 to check the ranking of each company. The average of HCE, SCE, CEE and VAIC for each year is calculated and analyzed for growth.

5. Company wise ranking of VAIC, Sales, and Profits are compared. This is done to test if the Sales/Profits \& VAIC are related

\section{Results and Discussion}

Following the methodology, we calculate the VA, HCE, SCE, CEE, and VAIC of each company separately from 2008-09 to 2019-20.

Using Path Analysis, we proceed to check if the VAIC and its components have an impact on the profitability and Market Value. Two Path Analysis Models (Figures 3 and 4) are developed with ROCE (proxy to profitability) and MB Ratio (proxy to market valuation) as dependent variables. The models use ROA, Market Capitalization and Leverage as mediating variables.

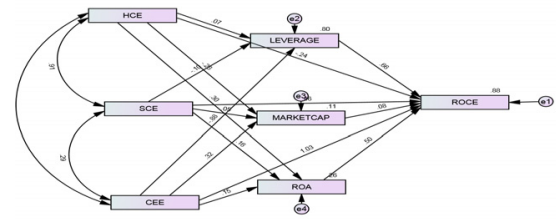

Figure 3: Path Analysis to test the impact of HCE, SCE and CEE on Profitability 


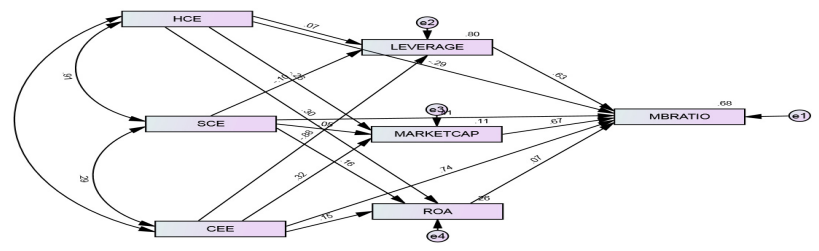

Figure 4: Path Analysis to test the impact of HCE, SCE and CEE on Market Valuation

Table 2: Results of Path Analysis

\begin{tabular}{|c|c|c|c|c|c|c|c|}
\hline \multicolumn{3}{|c|}{ Model } & $\begin{array}{c}\text { Unstandardized } \\
\text { Estimates }\end{array}$ & S.E. & C.R. & $\begin{array}{l}\text { Standardized } \\
\text { Estimates }\end{array}$ & $\mathbf{P}$ \\
\hline LEVERAGE & $<--$ & $\mathrm{HCE}$ & \begin{tabular}{|l|}
.089 \\
\end{tabular} & .084 & 1.066 & .070 & .287 \\
\hline LEVERAGE & $<---$ & SCE & -.243 & .167 & -1.457 & -.096 & .145 \\
\hline LEVERAGE & $<---$ & CEE & -.591 & .019 & -30.583 & -.884 & $* * *$ \\
\hline MARKETCAP & $<---$ & SCE & .452 & 1.207 & .374 & .052 & .708 \\
\hline MARKETCAP & $<---$ & HCE & -1.150 & .607 & -1.895 & -.262 & .058 \\
\hline MARKETCAP & $<--$ & CEE & .732 & .140 & 5.239 & .318 & $* * *$ \\
\hline $\mathrm{ROA}$ & $<---$ & CEE & .225 & .081 & 2.765 & .154 & .006 \\
\hline ROA & $<---$ & SCE & .861 & .703 & 1.223 & .155 & .221 \\
\hline ROA & $<--$ & HCE & .834 & .354 & 2.357 & .297 & .018 \\
\hline ROCE & $<---$ & $\mathrm{HCE}$ & -.458 & .099 & -4.613 & -.235 & $* * *$ \\
\hline ROCE & $<---$ & CEE & 1.046 & .049 & 21.558 & 1.028 & $* * *$ \\
\hline ROCE & $<---$ & SCE & 1.775 & .195 & 9.099 & .461 & $* * *$ \\
\hline ROCE & $<---$ & LEVERAGE & 1.008 & .072 & 14.097 & .662 & $* * *$ \\
\hline ROCE & $<---$ & MARKETCAP & .034 & .010 & 3.479 & .078 & $* * *$ \\
\hline ROCE & $<---$ & $\mathrm{ROA}$ & .344 & .017 & 20.278 & .496 & $* * *$ \\
\hline MBRATIO & $<--$ & HCE & -.562 & .166 & -3.385 & -.235 & $* * *$ \\
\hline MBRATIO & $<---$ & CEE & .762 & .081 & $9 \cdot 387$ & 1.028 & $* * *$ \\
\hline MBRATIO & $<---$ & SCE & 1.594 & .326 & 4.887 & .461 & $* * *$ \\
\hline MBRATIO & $<---$ & LEVERAGE & .972 & .120 & 8.126 & .662 & $* * *$ \\
\hline MBRATIO & $<--$ & MARKETCAP & .299 & .017 & 18.075 & .078 & $* * *$ \\
\hline MBRATIO & $<---$ & ROA & .049 & .028 & 1.719 & .496 & .086 \\
\hline
\end{tabular}

Outcome of the Path Analysis is given in Table 2 above, after eliminating overlapping results. The results indicate that HCE and SCE do not have an impact on the leverage. Only CEE has a negative impact on leverage, meaning, higher the efficiency of physical assets, lesser will be the dependence on leverage. Further, HCE and CEE influence the market capitalization whereas SCE does not. Looking at the ROA, both HCE and CEE impact the ROA whereas SCE does not. All three components of VAIC i.e., HCE, SCE and CEE impact the ROCE as well as MB ratio. Leverage, Market capitalization and ROA being mediating variables also have an influence on ROCE as well as the MB Ratio. However, the explanatory power of the bearing on market valuation (with $\mathrm{R}^{2}$ of 0.68 ) is not as strong as the explanatory power of ROCE ( $\mathrm{R}^{2}$ of 0.88$)$. 
After establishing the impact of VAIC and its components on ROCE and MB Ratio, we proceed to analyze the company wise and year wise performance of HCE, SCE, CEE and VAIC. To achieve this, the average of each year is taken and to get the company wise ranking, the result of each element is sorted by the year 2020 .

Company wise and year wise HCE is shown in Annexure 1 and the Average HCE is shown in Figure 5. Looking at the individual companies, it is evident that Aarti drugs, Divi's Laboratories and Glaxo are top performers in HCE, while Strides, Glenmark and Lupin are the performers with lowest HCE scores.

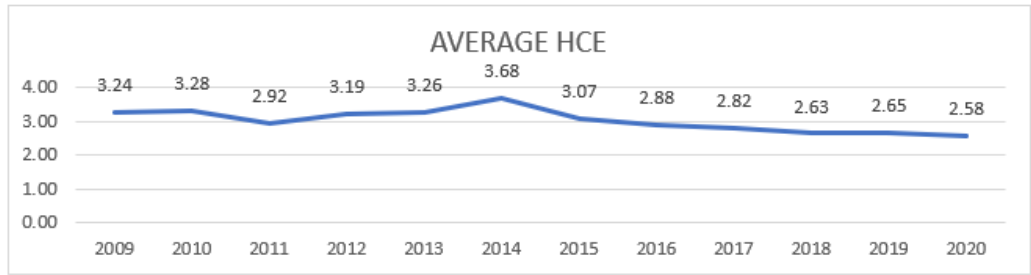

Figure 5: Average HCE of the companies

The average HCE (Figure 5) seems to have declined from the high of 3.24 in 2009 to 2.58 in 2020 . In the year 2014, the HCE had peaked to 3.68

Company wise and year wise SCE is shown in Annexure 2. SCE is sorted by year 2020. The ranking of SCE is same as HCE, with Aarti, Divi's and Glaxo taking the first three ranks, while Strides, Glenmark and Lupin taking the lowest ranks

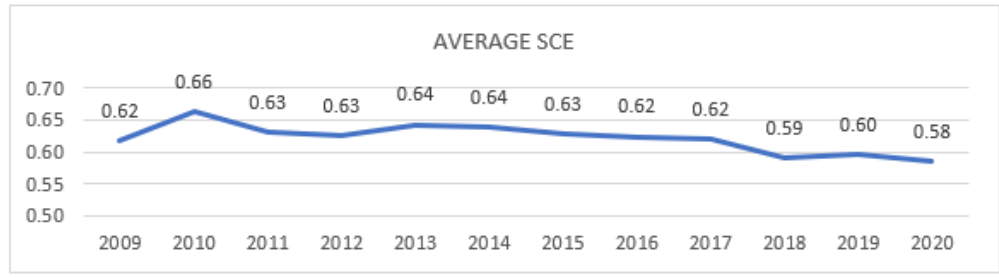

\section{Figure 6: Average SCE of companies}

As seen in Figure 6 above, the average SCE has slightly dipped in the latter years. The dip in 2020 could be attributed to COVID, as most of the pharma companies performed low during the $4^{\text {th }}$ quarter of FY 2020.

Company wise and year wise CEE is shown in Annexure 3. CEE is sorted by year 2020. Looking at the ranking of individual companies, Divi's, JB and Ajantha take the top 3 ranks whereas Cadila, Aarti \& Strides take the lowest 3 ranks.

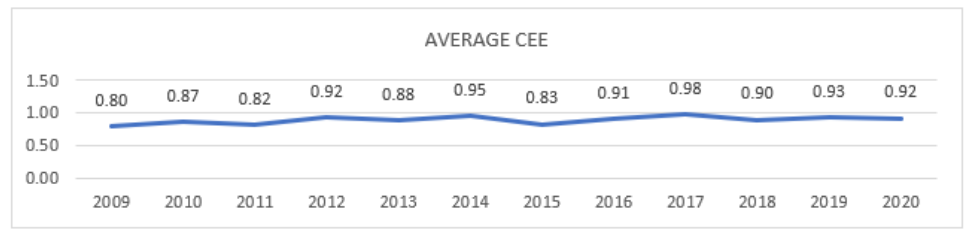

Figure 7: Average CEE of companies 
An improvement in the CEE is observed over the years. This is due to heavy investments in plant \& machinery and research facilities by companies. As shown by Figure 7 above, from 0.80 in 2009, the average CEE has grown to 0.92 in 2020.

Annexure 4 shows company wise and year wise VAIC which is sorted by year 2020. It is observed that Divi's, Aarti \& Glaxo took the top 3 ranks while Glenmark, Lupin \& Strides were at the lower end of the table.

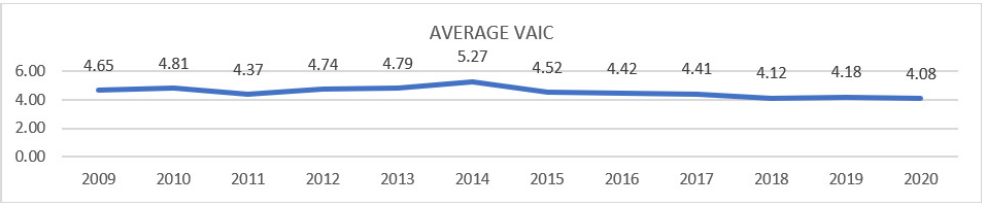

Figure 8: Average VAIC from 2009 to 2020

There is a decline in the average VAIC from 2009 to 2020, as shown by Figure 8 above. This is due to the decline in HCE and SCE over the years, while CEE has gained.

Following levels of efficiency are described by Public (2004): 2.50 (Or more) - means very successful business; 2.00 - Floor level for resourceful operations in business; 1.75 -Business is doing reasonably well but cannot ensure prolonged sustainability; 1.25 - This is a worrying situation where the continuation of the business is at stake; 1.00 - A disturbing situation where the continuation of the business is on the edge.

If we apply the above benchmark to the VAIC obtained in 2020 (Annexure 4), it can be concluded that most companies (except Strides Pharma, which shows a score of 2.47) fall in the first category of $\mathbf{2 . 5 0}$ or more, indicating very successful and safe businesses.

Annexure 5 shows the ranking of companies based on VAIC, HCE \& SCE and CEE. As VAIC is the combination of $\mathrm{HCE}+\mathrm{SCE}+\mathrm{CEE}$, all three elements are added up to arrive at the score and ranking of VAIC. Though Divi's Lab is in the $2^{\text {nd }}$ position in HCE + SCE, because of its No. 1 position in CEE, the company has got the top slot in VAIC. Similarly, though Aarti drugs is $21^{\text {st }}$ on the ranking of CEE, the company's No. 1 position in HCE + SCE has given it the second rank in VAIC.

As discussed earlier in the paper, higher sales and higher profits need not necessarily result in higher VAIC, as VAIC is an indicator of efficiency of Intellectual as well as physical capital. To establish this, we rank the sales and profits before tax of all selected companies. Annexure 6 shows the ranking of VAIC corresponding to the ranking of sales and profit before tax. The results indicate that higher sales and profits are no indication of higher VAIC. Divi's Lab which tops in VAIC ranking is $11^{\text {th }}$ in terms of sales and $5^{\text {th }}$ in terms of profit before tax. Similarly, Sun Pharmaceuticals which has highest sales and profits is $15^{\text {th }}$ on the ranking of VAIC. Aurobindo Pharma which is $2^{\text {nd }}$ in terms of sales and profits is $11^{\text {th }}$ on VAIC ranking.

Annexure 7 shows the contribution of HCE, SCE and CEE to the VAIC over the years. It is observed that the contribution of HCE has come down over the years from $69.59 \%$ in 2009 to $63.15 \%$ in 2020, whereas, the contribution of SCE and CEE have increased. Increase in SCE is due to development of new drugs and formulations resulting in increased patents, acquisition of new technology, spend on R\&D etc. Similarly, increase in CEE from $17.12 \%$ in 2009 to $22.52 \%$ in 2020 could be attributed to increased capital expenditure on capacity expansion and increased production.

\section{Conclusion}

The role of Intellectual Capital has been growing in the business world over the years. The role is specially more pronounced in Knowledge based industries like Information Technology, Pharmaceuticals, Education, Hospitality etc. India is one of the leading producers of pharmaceuticals 
in the world. With the cost of production that is low (approximately $33 \%$ lower than that of the US), the continued R\&D investments by Pharma companies and the boost that is given by the government of India, the competitive advantage of India has increased over the years. This has led to increased exports of pharmaceutical products to the rest of the world (exports reached US\$ 16.28 billion in FY 2020). Indian pharma exports reach more than 200 countries in the world, the US being the top export destination. India has a fantastic pool of technically qualified biotech and pharmaceutical workforce and is second in the world in terms of workforce and its quality. Indian pharma sector is expected to grow at a CAGR of $\mathbf{2 2 . 4 \%}$. Based on the growing importance of Intellectual Capital (IC) in the Pharmaceutical Industry, especially after the implementation of TRIPS agreement in 2005, this study employs the measure of Value-Added Intellectual Coefficient (VAIC) to compute VAIC and its elements in the companies shortlisted for the study.

As the calculation of VAIC requires that profit is made in each year under study, only 22 companies are selected that represent $78 \%$ of the sales of the listed pharmaceutical companies in India. As the major growth in Indian Pharma sector occurred after the implementation of TRIPS agreement in 2005, to see the impact of TRIPS, the study selects 12 years i.e. From financial year 2008o9 up to financial year 2019-20. By employing VAIC method, first of all Value Added (VA) is calculated for each company. The calculation of VA follows the calculation of HCE, SCE and CEE. All three elements together form VAIC. With the help of Path Analysis, the impact of VAIC on profitability and Market Valuation is verified. The study ranks the companies by the score of VAIC \& its elements. VAIC is also compared with Sales and profits of companies to see whether more profitable companies have more VAIC.

In the Path Analysis, the study employs leverage, ROA, and market capitalization as mediating variables. The results show that the components of VAIC have a bearing on the ROCE and Market Valuation of companies. HCE and SCE do not show any bearing on the Leverage whereas CEE has a negative impact. However, the explanatory power of the bearing on market valuation (with $\mathrm{R}^{2}$ of $0.68)$ is not as strong as the explanatory power of ROCE ( $\mathrm{R}^{2}$ of 0.88$)$.

It is observed that HCE is the biggest component in the VAIC followed by CEE and SCE, respectively. The portion of CEE and SCE in the VAIC has increased over the years, whereas HCE has slightly decreased. This clearly indicates that the companies have been spending on acquiring greater structural capital by way of development of new formulation, acquiring patents etc. and consequently increasing their production capacities. By ranking the VAIC along with sales and profits, the study clearly shows that higher sales and profits need not necessarily result in higher VAIC, as the components of VAIC are clearly a measurement of efficiency of Physical and Intellectual Capital.

The paper clearly brings out the importance of Intellectual Capital in the Indian Pharma Industry. As HCE is the largest element in the VAIC, it shows the importance of the pool of skilled human resources in the development of the industry. The increasing trend in SCE and CEE is in correlation with the increasing investment in Structural Capital and capacity expansion by companies. There seems to be an improvement on the explanation on market valuation as compared to earlier studies, especially the results obtained in studies by Tandon \& Purohit (2015), Mehralian et al (2012) and Ghosh \& Mondal (2009). As most of the other studies were conducted prior to 2012, it can only be assumed that since the implementation of TRIPS agreement in 2005, the pharma industry has increasingly relied on Intellectual Capital and has worked on improving the efficiency, which is now reflecting in better market pricing and profitability.

As the concept of VAIC is recently developed, this paper adds to the existing literature, especially in the Indian context. There is scope to examine VAIC and its components in the Indian Pharma industry by studying the periods before and after the implementation of TRIPS agreement in 2005. There is also a scope to examine the influence of quality of management and directorship on the VAIC of the industry. This is left to future research. 


\section{References}

Forte W, Matoni G, Nicolo G, Tucker J (2019). MtB versus VAIC in measuring intellectual capital: Empirical evidence from Italian listed companies. African Journal of Business Management 13(17):588-601

Ghosh, S.K. and Maji S.G. (2012), "Impact of Intellectual Capital on Firm Performance: An Empirical Study on Chemical and Banking Sector in India", Indore Management Journal, Special Issue, pp. 42- 55.

Ghosh, S.K. and S.G. Maji (2015), "Empirical Validity of Value-Added Intellectual Coefficient Model in Indian Knowledge Based Sector", Global Business Review, Vol. 16, No. 6, pp. 947-962

Ghosh, S. and Mondal, A. (2009), "Indian software and pharmaceutical sector IC and financial performance", Journal of Intellectual Capital, Vol. 10 No. 3, pp. 369-88.

$\mathrm{Gu}$, F. and Lev, B., (2017). Time to change your investment model. Financial Analysts Journal, 73, 23-33.

Kamath, B. (2008). Intellectual capital and corporate performance in Indian pharmaceutical industry. Journal of Intellectual Capital, Vol. 9 No. 4, pp. 684-704

Kamath, B. (2015). Impact of Intellectual capital on Financial Performance and Market Valuation of Firms in India. International letters of Social and Humanistic Sciences Vol. 48. Pp 107-122

Maji, SG \& Chakrabarty TK (2019). Heterogeneity in the Intellectual Capital and Performance of Indian Commercial Banks: Panel Data, Quantile Regression Analysis. Bank Parikrama. Volume XLIV, Nos. 1 \& 2, pp. 27-52

Mehralian, G., Rajabzadeh, A., Sadegh, M.R. \& Rasekh, H.R. (2012). Intellectual capital and corporate performance in Iranian pharmaceutical industry. Journal of Intellectual Capital. 13 (1), pp. 138-158

Nagaraja N \& Vinay N (2016). The Effect of Intangible Assets on the Firm Value. International Journal of Engineering and Management Research. Volume-6 (1). Pp. 307-315

Pulic A (1998), "Measuring the Performance of Intellectual Capital in Knowledge Economy", available at www.measuring-ip.at/Papers/Pulic/Vaictxt.vaictxt.html.

'Pulic A (2000a), "VAIC: An Accounting Tool for IC Management", International Journal of Technology Management, Vol. 20, Nos. 5/6/7/8, pp. 545-55.

Pulic A (200ob), "MVA and VAIC Analysis of Randomly Selected Companies from FTSE 250", available at vaicon.net/downloads/ftsezo.pdf

Pulic, A. (2004), "Intellectual capital - does it create or destroy value?", Measuring Business Excellence, Vol. 8 No. 1, pp. 62-8.

Pulic, A. (2005), Value Creation Efficiency at National and Regional Levels: Case Study - Croatia and The European Union, in A. Bounfour \& L. Edvinsson (Eds), Intellectual Capital for Communities, Elsevier, Oxford.

Puntilo, P. (2009), "Intellectual capital and business performance: evidence from Italian banking industry", Journal of Corporate Finance, Vol. 12 No. 4, pp. 97-115.

Tandon K \& Purohit, H. (2015). Intellectual Capital, Financial Performance and Market Valuation: A Study on IT and Pharmaceutical Companies in India. The IUP Journal of Knowledge Management. Vol. XIII - 2, pp. 7-24.

Shaban, M. \& Kavida, V. (2013), "Intellectual Capital, Financial Performance and Market Valuation: An Empirical Investigation of Information Technology Industry in India", Asia Pacific Journal of Management Research and Innovation, Vol. 9, No. 1, pp. 55-62.

Stahle P, Aho S \& Stahle S (2011). Value Added Intellectual Coefficient (VAIC): a critical analysis. Journal of Intellectual Capital.

Stewart T.A. (1991). Brainpower. How Intellectual Capital is becoming America's Most Valuable Asset. Fortune Magazine. $3^{\text {rd June,1991. }}$

Xu, J., \& Liu, F. (2020). The Impact of Intellectual Capital on Firm Performance: A Modified and Extended VAIC Model. Journal of Competitiveness, 12(1), 161-176.

Appendix 1: Ranking of HCE (sorted by year 2020)

\begin{tabular}{|c|c|c|c|c|c|c|c|c|c|c|c|c|}
\hline YEAR & 2009 & 2010 & 2011 & 2012 & 2013 & 2014 & 2015 & 2016 & 2017 & 2018 & 2019 & 2020 \\
\hline AARTI & 6.12 & 5.96 & $4 \cdot 77$ & 6.76 & $5 \cdot 33$ & 4.44 & 6.26 & 4.95 & 5.06 & 4.26 & 4.49 & $4 \cdot 75$ \\
\hline DIVI'S & 6.32 & 5.47 & 5.49 & 5.95 & $5 \cdot 35$ & 5.67 & 5.17 & 5.20 & 4.04 & 4.01 & $4 \cdot 74$ & 4.23 \\
\hline GLAXO & 2.89 & 2.93 & 2.99 & 3.16 & 3.28 & 3.28 & $3 \cdot 30$ & 3.21 & 3.21 & $3 \cdot 39$ & 3.16 & 3.44 \\
\hline PFIZER & 5.09 & 2.56 & 2.56 & 2.50 & $4 \cdot 33$ & 2.82 & 2.94 & 2.90 & 2.91 & 2.95 & 3.26 & 3.07 \\
\hline GRANULES & 2.95 & 3.56 & 2.63 & 2.74 & 2.36 & 2.63 & 2.75 & 3.06 & 3.07 & 2.61 & 2.91 & 3.04 \\
\hline NATCO & 2.54 & 2.65 & 2.43 & 2.49 & 2.47 & 2.74 & 2.54 & 2.55 & 3.86 & 3.97 & 3.60 & 2.84 \\
\hline TORRENT & 2.06 & 2.40 & 2.00 & 1.90 & 2.11 & 2.32 & 2.54 & 4.22 & 2.60 & 2.44 & 2.19 & 2.60 \\
\hline
\end{tabular}




\begin{tabular}{|c|c|c|c|c|c|c|c|c|c|c|c|c|}
\hline AJANTHA & 2.59 & 2.67 & 2.40 & 2.47 & 2.87 & 3.44 & 3.56 & 3.37 & 3.40 & 2.81 & 2.35 & 2.58 \\
\hline AUROBINDO & 2.41 & 3.98 & 3.41 & 1.49 & 2.34 & 3.69 & 3.04 & 3.20 & 3.01 & 2.82 & 2.56 & 2.56 \\
\hline SANOFI & 3.33 & 2.79 & 3.04 & 2.79 & 2.65 & 2.98 & 2.63 & 2.78 & 2.69 & 2.68 & 2.76 & 2.56 \\
\hline JB CHEM & 1.73 & 2.73 & 2.58 & 8.88 & 2.02 & 1.84 & 2.20 & 2.50 & 2.30 & 2.01 & 2.21 & 2.29 \\
\hline BIOCON & 2.29 & 3.07 & 3.60 & 2.88 & 3.04 & 2.54 & 2.50 & 2.68 & 2.54 & 2.13 & 2.48 & 2.23 \\
\hline CIPLA & 5.05 & 5.76 & 3.58 & 3.33 & 3.37 & 2.55 & 2.18 & 2.10 & 2.02 & 2.15 & 2.25 & 2.17 \\
\hline SUN & 7.11 & 4.93 & 3.83 & 4.09 & 4.06 & 3.43 & 2.82 & 2.70 & 3.19 & 2.02 & 2.03 & 2.16 \\
\hline IPCA LABS & 2.06 & 2.57 & 2.61 & 2.42 & 2.47 & 2.53 & 2.01 & 1.50 & 1.66 & 1.68 & 1.95 & 2.05 \\
\hline CADILA & 2.71 & 2.88 & 2.54 & 2.45 & 2.25 & 2.13 & 2.45 & 2.88 & 2.33 & 2.58 & 2.49 & 2.05 \\
\hline DR. REDDY & 0.95 & 1.90 & 2.26 & 2.53 & 2.46 & 2.38 & 2.28 & 2.24 & 1.85 & 1.78 & 2.06 & 1.93 \\
\hline JUBILANT & 2.17 & 1.95 & 1.75 & 1.68 & 1.94 & 1.75 & 1.64 & 2.12 & 2.11 & 2.00 & 1.78 & 1.92 \\
\hline STRIDES & 2.33 & 2.48 & 2.77 & 2.89 & 9.80 & 20.44 & $7 \cdot 41$ & 2.22 & 2.95 & 3.40 & 2.52 & 1.84 \\
\hline GLENMARK & 2.81 & 3.23 & 2.44 & 2.17 & 2.31 & 2.07 & 1.85 & 2.06 & 2.21 & 1.91 & 1.95 & 1.84 \\
\hline LUPIN & 2.53 & 2.70 & 2.56 & 2.50 & 2.81 & 3.13 & 3.21 & 2.81 & 2.62 & 1.64 & 1.96 & 1.74 \\
\hline AVERAGE & 3.24 & 3.28 & 2.92 & 3.19 & 3.26 & 3.68 & 3.07 & 2.88 & 2.82 & 2.63 & 2.65 & 2.58 \\
\hline
\end{tabular}

Appendix 2: Ranking of SCE (sorted by 2020)

\begin{tabular}{|l|l|l|l|l|l|l|l|l|l|l|l|l|}
\hline YEAR & $\mathbf{2 0 0 9}$ & $\mathbf{2 0 1 0}$ & $\mathbf{2 0 1 1}$ & $\mathbf{2 0 1 2}$ & $\mathbf{2 0 1 3}$ & $\mathbf{2 0 1 4}$ & $\mathbf{2 0 1 5}$ & $\mathbf{2 0 1 6}$ & $\mathbf{2 0 1 7}$ & $\mathbf{2 0 1 8}$ & $\mathbf{2 0 1 9}$ & $\mathbf{2 0 2 0}$ \\
\hline AARTI & 0.84 & 0.83 & 0.79 & 0.85 & 0.81 & 0.77 & 0.84 & 0.80 & 0.80 & 0.77 & 0.78 & 0.79 \\
DIVI'S & 0.84 & 0.82 & 0.82 & 0.83 & 0.81 & 0.82 & 0.81 & 0.81 & 0.75 & 0.75 & 0.79 & 0.76 \\
GLAXO & 0.65 & 0.66 & 0.67 & 0.68 & 0.70 & 0.70 & 0.70 & 0.69 & 0.69 & 0.70 & 0.68 & 0.71 \\
PFIZER & 0.80 & 0.61 & 0.61 & 0.60 & 0.77 & 0.64 & 0.66 & 0.66 & 0.66 & 0.66 & 0.69 & 0.67 \\
GRANULES & 0.66 & 0.72 & 0.62 & 0.64 & 0.58 & 0.62 & 0.64 & 0.67 & 0.67 & 0.62 & 0.66 & 0.67 \\
NATCO & 0.61 & 0.62 & 0.59 & 0.60 & 0.59 & 0.63 & 0.61 & 0.61 & 0.74 & 0.75 & 0.72 & 0.65 \\
ABBOTT & 0.68 & 0.67 & 0.49 & 0.54 & 0.54 & 0.52 & 0.55 & 0.55 & 0.57 & 0.62 & 0.62 & 0.64 \\
TORRENT & 0.52 & 0.58 & 0.50 & 0.47 & 0.53 & 0.57 & 0.61 & 0.76 & 0.61 & 0.59 & 0.54 & 0.61 \\
AJANTHA & 0.61 & 0.63 & 0.58 & 0.60 & 0.65 & 0.71 & 0.72 & 0.70 & 0.71 & 0.64 & 0.57 & 0.61 \\
AUROBINDO & 0.58 & 0.75 & 0.71 & 0.33 & 0.57 & 0.73 & 0.67 & 0.69 & 0.67 & 0.65 & 0.61 & 0.61 \\
SANOFI & 0.70 & 0.64 & 0.67 & 0.64 & 0.62 & 0.66 & 0.62 & 0.64 & 0.63 & 0.63 & 0.64 & 0.61 \\
JB CHEM & 0.42 & 0.63 & 0.61 & 0.89 & 0.51 & 0.46 & 0.55 & 0.60 & 0.56 & 0.50 & 0.55 & 0.56 \\
BIOCON & 0.56 & 0.67 & 0.72 & 0.65 & 0.67 & 0.61 & 0.60 & 0.63 & 0.61 & 0.53 & 0.60 & 0.55 \\
CIPLA & 0.80 & 0.83 & 0.72 & 0.70 & 0.70 & 0.61 & 0.54 & 0.52 & 0.51 & 0.54 & 0.55 & 0.54 \\
SUN & 0.86 & 0.80 & 0.74 & 0.76 & 0.75 & 0.71 & 0.64 & 0.63 & 0.69 & 0.51 & 0.51 & 0.54 \\
IPCA LABS & 0.51 & 0.61 & 0.62 & 0.59 & 0.60 & 0.61 & 0.50 & 0.33 & 0.40 & 0.40 & 0.49 & 0.51 \\
CADILA & 0.63 & 0.65 & 0.61 & 0.59 & 0.56 & 0.53 & 0.59 & 0.65 & 0.57 & 0.61 & 0.60 & 0.51 \\
DR. REDDY & 0.05 & 0.47 & 0.56 & 0.60 & 0.59 & 0.58 & 0.56 & 0.55 & 0.46 & 0.44 & 0.51 & 0.48 \\
JUBILANT & 0.54 & 0.49 & 0.43 & 0.41 & 0.48 & 0.43 & 0.39 & 0.53 & 0.53 & 0.50 & 0.44 & 0.48 \\
STRIDES & 0.57 & 0.60 & 0.64 & 0.65 & 0.90 & 0.95 & 0.87 & 0.55 & 0.66 & 0.71 & 0.60 & 0.46 \\
GLENMARK & 0.64 & 0.69 & 0.59 & 0.54 & 0.57 & 0.52 & 0.46 & 0.51 & 0.55 & 0.48 & 0.49 & 0.46 \\
LUPIN & 0.60 & 0.63 & 0.61 & 0.60 & 0.64 & 0.68 & 0.69 & 0.64 & 0.62 & 0.39 & 0.49 & 0.43 \\
\hline AVERAGE & $\mathbf{0 . 6 2}$ & $\mathbf{0 . 6 6}$ & $\mathbf{0 . 6 3}$ & $\mathbf{0 . 6 3}$ & $\mathbf{0 . 6 4}$ & $\mathbf{0 . 6 4}$ & $\mathbf{0 . 6 3}$ & $\mathbf{0 . 6 2}$ & $\mathbf{0 . 6 2}$ & $\mathbf{0 . 5 9}$ & $\mathbf{0 . 6 0}$ & $\mathbf{0 . 5 8}$ \\
\hline
\end{tabular}

Appendix 3: Ranking of CEE (sorted by 2020)

\begin{tabular}{|l|l|l|l|l|l|l|l|l|l|l|l|l|}
\hline YEAR & $\mathbf{2 0 0 9}$ & $\mathbf{2 0 1 0}$ & $\mathbf{2 0 1 1}$ & $\mathbf{2 0 1 2}$ & $\mathbf{2 0 1 3}$ & $\mathbf{2 0 1 4}$ & $\mathbf{2 0 1 5}$ & $\mathbf{2 0 1 6}$ & $\mathbf{2 0 1 7}$ & $\mathbf{2 0 1 8}$ & $\mathbf{2 0 1 9}$ & $\mathbf{2 0 2 0}$ \\
\hline DIVI'S & 1.95 & 1.58 & 1.35 & 1.44 & 1.66 & 1.76 & 1.65 & 3.11 & 2.53 & 2.13 & 2.38 & 2.16 \\
JB & 0.61 & 1.07 & 1.05 & 4.39 & 0.94 & 0.86 & 0.72 & 0.95 & 1.61 & 1.56 & 2.04 & 1.96 \\
AJANTHA & 0.37 & 0.41 & 0.58 & 0.66 & 1.09 & 1.52 & 2.34 & 3.00 & 3.94 & 2.75 & 2.44 & 1.82 \\
SANOFI & 1.68 & 1.47 & 1.26 & 1.27 & 1.33 & 1.36 & 1.02 & 1.19 & 1.45 & 1.31 & 1.47 & 1.43 \\
NATCO & 0.53 & 0.63 & 0.45 & 0.46 & 0.46 & 0.66 & 0.65 & 0.87 & 1.41 & 2.01 & 1.57 & 1.31 \\
ABBOTT & 1.14 & 1.60 & 1.45 & 1.42 & 1.66 & 1.75 & 1.51 & 1.79 & 1.18 & 1.43 & 1.24 & 1.22 \\
IPCA LABS & 0.52 & 0.76 & 0.81 & 0.76 & 0.85 & 1.01 & 0.71 & 0.58 & 0.77 & 0.86 & 1.08 & 1.15 \\
GLAXO & 1.68 & 1.58 & 1.18 & 0.91 & 0.90 & 0.83 & 0.97 & 0.73 & 0.95 & 0.83 & 0.87 & 1.12 \\
PFIZER & 2.72 & 1.71 & 2.64 & 1.74 & 2.51 & 1.70 & 1.09 & 1.11 & 1.05 & 0.92 & 1.14 & 1.11 \\
DR. REDDY & 0.25 & 0.64 & 0.60 & 0.64 & 0.68 & 0.73 & 0.78 & 0.90 & 0.61 & 0.59 & 0.83 & 0.87 \\
CIPLA & 0.59 & 1.32 & 1.05 & 1.50 & 1.32 & 1.18 & 0.88 & 0.54 & 0.64 & 0.69 & 0.74 & 0.86 \\
AUROBINDO & 0.20 & 0.44 & 0.42 & 0.21 & 0.33 & 0.52 & 0.51 & 0.57 & 0.78 & 0.65 & 0.53 & 0.69 \\
GRANULES & 0.23 & 0.49 & 0.43 & 0.39 & 0.37 & 0.41 & 0.43 & 0.46 & 0.51 & 0.36 & 0.48 & 0.63 \\
JUBILANT & 0.28 & 0.32 & 0.24 & 0.26 & 0.32 & 0.31 & 0.29 & 0.41 & 0.48 & 0.58 & 0.53 & 0.61 \\
SUN & 2.21 & 1.76 & 1.14 & 1.19 & 1.16 & 0.67 & 0.55 & 0.57 & 0.64 & 0.42 & 0.52 & 0.60 \\
GLENMARK & 0.31 & 0.39 & 0.43 & 0.41 & 0.43 & 0.39 & 0.34 & 0.43 & 0.50 & 0.48 & 0.52 & 0.48 \\
LUPIN & 0.48 & 0.63 & 0.70 & 0.62 & 0.98 & 1.43 & 1.34 & 0.54 & 0.59 & 0.38 & 0.39 & 0.42
\end{tabular}




\begin{tabular}{|l|l|l|l|l|l|l|l|l|l|l|l|l|}
\hline YEAR & $\mathbf{2 0 0 9}$ & $\mathbf{2 0 1 0}$ & $\mathbf{2 0 1 1}$ & $\mathbf{2 0 1 2}$ & $\mathbf{2 0 1 3}$ & $\mathbf{2 0 1 4}$ & $\mathbf{2 0 1 5}$ & $\mathbf{2 0 1 6}$ & $\mathbf{2 0 1 7}$ & $\mathbf{2 0 1 8}$ & $\mathbf{2 0 1 9}$ & $\mathbf{2 0 2 0}$ \\
\hline BIOCON & 0.40 & 0.64 & 0.55 & 0.53 & 0.69 & 0.45 & 0.46 & 0.37 & 0.42 & 0.41 & 0.48 & 0.42 \\
TORRENT & 0.53 & 0.68 & 0.59 & 0.55 & 0.57 & 0.56 & 0.40 & 0.67 & 0.50 & 0.29 & 0.33 & 0.40 \\
CADILA & 0.43 & 0.59 & 0.70 & 0.50 & 0.47 & 0.51 & 0.63 & 0.81 & 0.44 & 0.53 & 0.41 & 0.38 \\
AARTI & 0.17 & 0.19 & 0.20 & 0.28 & 0.37 & 0.25 & 0.30 & 0.30 & 0.31 & 0.28 & 0.31 & 0.37 \\
STRIDES & 0.26 & 0.21 & 0.19 & 0.22 & 0.33 & 2.15 & 0.64 & 0.13 & 0.19 & 0.30 & 0.14 & 0.17 \\
\hline AVERAGE & $\mathbf{0 . 8 0}$ & $\mathbf{0 . 8 7}$ & $\mathbf{0 . 8 2}$ & $\mathbf{0 . 9 2}$ & $\mathbf{0 . 8 8}$ & $\mathbf{0 . 9 5}$ & $\mathbf{0 . 8 3}$ & $\mathbf{0 . 9 1}$ & $\mathbf{0 . 9 8}$ & $\mathbf{0 . 9 0}$ & $\mathbf{0 . 9 3}$ & $\mathbf{0 . 9 2}$ \\
\hline
\end{tabular}

Appendix 4: Summary \& Ranking of VAIC (sorted by 2020)

\begin{tabular}{|c|c|c|c|c|c|c|c|c|c|c|c|c|}
\hline YEAR & 2009 & 2010 & 2011 & 2012 & 2013 & 2014 & 2015 & 2016 & 2017 & 2018 & 2019 & 2020 \\
\hline DIVI'S & 9.10 & 7.86 & 7.66 & 8.22 & 7.83 & 8.26 & 7.62 & 9.11 & $7 \cdot 33$ & 6.89 & 7.91 & 7.15 \\
\hline AARTI & 7.12 & 6.99 & $5 \cdot 75$ & 7.89 & 6.52 & 5.47 & $7 \cdot 39$ & 6.05 & 6.17 & $5 \cdot 31$ & $5 \cdot 58$ & 5.91 \\
\hline GLAXO & 5.23 & 5.16 & 4.83 & 4.74 & 4.88 & 4.80 & 4.96 & 4.62 & 4.85 & 4.93 & 4.71 & 5.27 \\
\hline AJANTHA & 3.58 & 3.71 & 3.56 & 3.73 & 4.61 & 5.67 & 6.62 & 7.07 & 8.05 & 6.21 & $5 \cdot 36$ & 5.00 \\
\hline PFIZER & 8.61 & 4.88 & 5.81 & 4.85 & 7.61 & 5.16 & 4.69 & 4.67 & 4.62 & $4 \cdot 54$ & 5.09 & 4.85 \\
\hline $\mathrm{JB}$ & 2.77 & 4.43 & 4.24 & 14.16 & 3.47 & 3.16 & 3.46 & 4.05 & 4.47 & 4.08 & $4 \cdot 79$ & 4.82 \\
\hline NATCO & 3.68 & 3.89 & $3 \cdot 47$ & 3.54 & 3.52 & 4.03 & 3.79 & 4.02 & 6.01 & 6.73 & 5.89 & 4.80 \\
\hline АВВОТТ & 4.99 & $5 \cdot 34$ & 3.90 & 4.15 & 4.38 & 4.33 & 4.26 & 4.56 & 4.05 & 4.67 & 4.49 & 4.64 \\
\hline SANOFI & $5 \cdot 72$ & 4.90 & 4.97 & 4.70 & 4.60 & 5.00 & 4.27 & 4.61 & $4 \cdot 77$ & 4.62 & 4.86 & 4.60 \\
\hline GRANULES & 3.84 & 4.77 & 3.68 & 3.77 & $3 \cdot 31$ & 3.66 & 3.82 & 4.19 & 4.25 & 3.59 & 4.05 & $4 \cdot 34$ \\
\hline AUROBINDO & 3.19 & 5.17 & 4.54 & 2.03 & 3.25 & 4.93 & 4.23 & 4.46 & 4.46 & 4.11 & 3.70 & 3.86 \\
\hline IPCA LABS & 3.09 & 3.93 & 4.04 & 3.76 & 3.92 & 4.15 & 3.22 & 2.41 & 2.83 & 2.94 & $3 \cdot 5^{2}$ & 3.72 \\
\hline TORRENT & 3.11 & 3.66 & 3.09 & 2.92 & 3.21 & 3.45 & 3.55 & 5.66 & 3.71 & 3.32 & 3.07 & 3.62 \\
\hline CIPLA & 6.45 & $7 \cdot 90$ & 5.35 & 5.53 & 5.40 & $4 \cdot 34$ & 3.60 & 3.17 & 3.17 & 3.37 & 3.54 & 3.57 \\
\hline SUN & 10.18 & 7.49 & 5.70 & 6.04 & 5.97 & 4.81 & 4.01 & 3.91 & 4.51 & 2.95 & 3.05 & 3.29 \\
\hline DR. REDDY & 1.15 & 3.01 & $3 \cdot 42$ & 3.77 & 3.73 & 3.69 & 3.62 & 3.70 & 2.92 & 2.80 & 3.40 & 3.28 \\
\hline BIOCON & 3.25 & $4 \cdot 39$ & 4.88 & 4.06 & 4.40 & 3.60 & 3.55 & 3.68 & 3.56 & 3.08 & 3.56 & 3.21 \\
\hline JUBILANT & 2.99 & 2.75 & 2.41 & 2.35 & 2.74 & 2.48 & 2.32 & 3.06 & 3.12 & 3.08 & 2.74 & 3.01 \\
\hline CADILA & 3.78 & 4.12 & 3.85 & 3.54 & 3.28 & 3.17 & 3.68 & $4 \cdot 33$ & 3.34 & 3.72 & 3.50 & 2.94 \\
\hline GLENMARK & 3.76 & 4.32 & 3.46 & 3.11 & 3.31 & 2.98 & 2.66 & 3.00 & 3.26 & 2.87 & 2.97 & 2.78 \\
\hline LUPIN & 3.61 & 3.96 & 3.87 & 3.72 & 4.44 & 5.24 & 5.24 & 3.99 & 3.82 & 2.41 & 2.84 & 2.59 \\
\hline STRIDES & 3.16 & 3.28 & 3.60 & 3.76 & 11.03 & 23.54 & 8.92 & 2.90 & 3.81 & 4.40 & 3.26 & 2.47 \\
\hline AVERAGE & 4.65 & 4.81 & $4 \cdot 37$ & $4 \cdot 74$ & $4 \cdot 79$ & 5.27 & 4.52 & 4.42 & 4.41 & 4.12 & 4.18 & 4.08 \\
\hline
\end{tabular}

Appendix 5: Rankings of HCE, SCE and CEE

\begin{tabular}{|l|c|c|c|}
\hline NAME & VAIC RANKING & HCE \& SCE RANKING & CEE RANKING \\
\hline DIVI'S & 1 & 2 & 1 \\
AARTI & 2 & 1 & 21 \\
GLAXO & 3 & 3 & 8 \\
AJANTHA & 4 & 9 & 3 \\
PFIZER & 5 & 4 & 9 \\
JB CHEMICALS & 6 & 12 & 2 \\
NATCO PHARMA & 7 & 6 & 5 \\
ABBOTT & 8 & 7 & 6 \\
SANOFI & 9 & 11 & 4 \\
GRANULES INDIA & 10 & 5 & 13 \\
AUROBINDO & 11 & 10 & 12 \\
IPCA LABS & 12 & 16 & 19 \\
TORRENT & 13 & 8 & 11 \\
CIPLA & 14 & 14 & 15 \\
SUN PHARMA & 15 & 15 & 10 \\
DR. REDDY'S & 16 & 18 & 18 \\
BIOCON & 17 & 13 & 14 \\
JUBILANT & 18 & 19 & 20 \\
CADILA HEALTH & 19 & 17 & 16 \\
GLENMARK & 19 & 21 & 17 \\
LUPIN & 20 & 22 & 22 \\
STRIDES & 21 & 20 & \\
\hline
\end{tabular}


Appendix 6: Ranking of VAIC, Sales and Profits

\begin{tabular}{|l|c|c|c|}
\hline NAME & VAIC RANKING & RANKING - SALES & RANKING- PROFIT \\
\hline DIVI'S & 1 & 11 & 5 \\
AARTI & 2 & 21 & $\mathbf{2 1}$ \\
GLAXO & 3 & 12 & 15 \\
AJANTHA & 4 & 18 & 16 \\
PFIZER & 5 & 19 & $\mathbf{2 0}$ \\
JB CHEMICALS & 6 & 22 & 18 \\
NATCO PHARMA & 7 & 20 & 13 \\
ABBOTT & 8 & 14 & 17 \\
SANOFI & 9 & 15 & $\mathbf{2}$ \\
GRANULES INDIA & 10 & 17 & $\mathbf{1 4}$ \\
AUROBINDO & 11 & 2 & 9 \\
IPCA LABS & 12 & 13 & 3 \\
TORRENT & 13 & 9 & 1 \\
CIPLA & 14 & 4 & 4 \\
SUN PHARMA & 15 & 1 & 10 \\
DR. REDDY'S & 16 & 3 & 8 \\
BIOCON & 17 & 10 & 7 \\
JUBILANT & 18 & 8 & 11 \\
CADILA HEALTH & 19 & 6 & $\mathbf{1 2}$ \\
GLENMARK & 20 & 7 & $\mathbf{2 2}$ \\
LUPIN & 21 & 5 & 16 \\
STRIDES & $\mathbf{2 2}$ & & \\
\hline
\end{tabular}

Appendix 7: Contribution of HCE, SCE and CEE to VAIC

\begin{tabular}{|c|c|c|c|}
\hline YEAR & \% HCE & \% Of SCE & \% Of CEE \\
\hline 2009 & 69.59 & 13.29 & 17.12 \\
2010 & 68.19 & 13.79 & 18.03 \\
2011 & 66.82 & 14.45 & 18.73 \\
2012 & 67.32 & 13.19 & 19.49 \\
2013 & 68.15 & 13.43 & 18.43 \\
2014 & 69.76 & 12.12 & 18.11 \\
2015 & 67.82 & 13.87 & 18.31 \\
2016 & 65.26 & 14.12 & 20.62 \\
2017 & 63.80 & 14.05 & 22.14 \\
2018 & 63.85 & 14.31 & 21.84 \\
2019 & 63.46 & 14.29 & 22.25 \\
2020 & 63.15 & 14.33 & 22.52 \\
\hline
\end{tabular}

